without white and without gaps, we have probably drops of $\mathrm{O}^{\prime} \mathrm{I} \mathrm{mm}$. ; in smaller drops, gaps and white make their appearance. A real white bow with yellow or orange and blue margins requires drops of not more than $0.05 \mathrm{~mm}$. Moonbows appear white owing to their feeble intensity. A small change in the size of big drops does not much matter. These

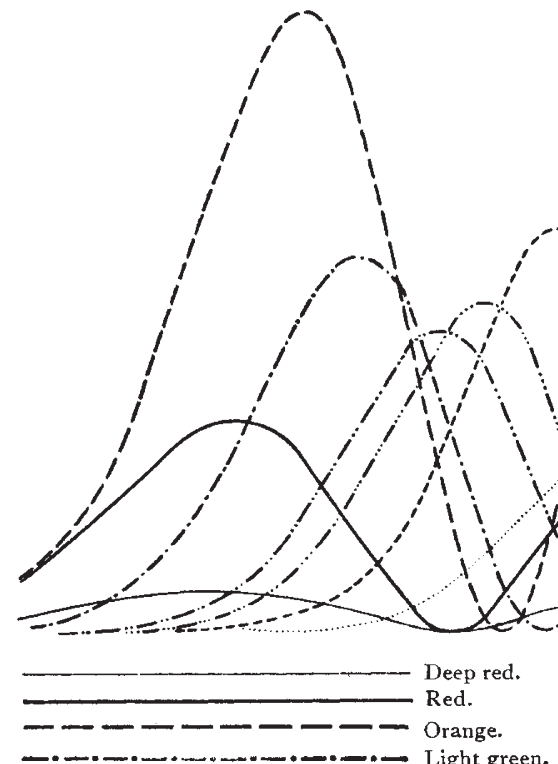

statements are based upon calculations and laboratory experiments; a confirmation by actual observations is hardly possible, since we cannot measure the size of the raindrops that produce the rainbows whose colours we are studying.

H. B.

\section{ON TRIBOLUMINESCENCE.}

$\mathrm{T}$

E name triboluminescence has been applied by E. Wiedemann to an emission of light not due to rise of temperature which occurs on crushing certain substances.

It has long been known that on tearing cleavage sheets of mica apart, or on crushing crystals of cane sugar, light is given out; and during the last few months attention has again been drawn to this curious phenomenon by a paper read before the British Association by Mr. J. Burke, on the luminosity produced by striking sugar crystals (NATURE, vol. Iviii. p. 533), and by Mr. T. Steel's letter to NATURE (vol. lix. p. 295) on the same subject. A brief account of other work done on the subject of triboluminescence during recent years may therefore be of interest.

Some years ago I contributed a paper to the Chemical Society (Trans. Chem. Soc., I 895, 985) on orthobenzoicsulphinide $\mathrm{C}_{6} \mathrm{H}_{4} / \mathrm{CO}_{2}>\mathrm{NH}$, the substance known commonly as saccharin, and which is now largely used as a substitute for sugar when the use of the latter is considered undesirable upon medical or other grounds. I showed that commercial saccharin crystallises, on spontaneous evaporation of its solution in acetone, in large, transparent, monosymmetric crystals having the geometrical constants :- $a: b: c=2 \cdot 7867: 1: 1 \cdot 7187, \beta=76^{\circ} 8^{\prime} 30^{\prime \prime}$. On breaking or crushing the freshly prepared crystals, they emit a very vivid, bluish-white light, which, however, is only of momentary duration. This flashing or phosphorescence of the crystals is very brilliant, and is quite noticeable even in a wellilluminated room. The luminescence was, in fact, first noticed whilst the crystals were being manipulated in the full glare of an ineandescent gas lamp. The phosphorescence may be well shown on a small scale by pulverising a crystal between two microscope slides, and on a larger scale by vigorously shaking a bottle of the crystals in a dark room ; on grinding a quantity of the material in a glass mortar in the dark, an almost con- tinuous, though rather fainter, luminescence is observed. On closely watching large transparent crystals whilst crushing them, the illumination appears to consist of a glow which pervades the whole crystal just as it breaks, and then immediately disappears; the emission of light consequently occupies so short a time as to appear instantaneous. The luminescence is not always apparent, and a crystal may sometimes be crushed in the dark without becoming appreciably luminous; these cases, however, are rare amongst freshly prepared crystals. On crushing twenty-three crystals, which had been found to be quite normal in optical and geometrical properties, only one refusad to flash, although no other point of difference between it and the other crystals could be established.

The method by which the crystals are broken seems without influence on the flashing ; luminescence occurs when the crystals are hacked with a knife, rubbed together, crushed between the fingers or between pieces of glass, and also when they are

Frg. 2.

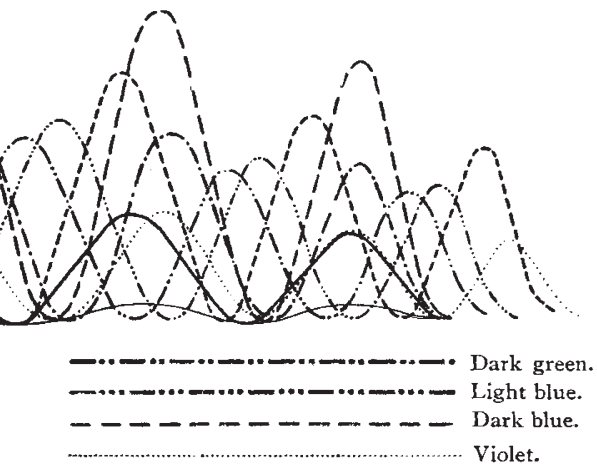

caused to crack by rapid heating, either in the air or in the acetone mother liquor from which they crystallise. There seems to be no particular plane in the crystal parallel to which breaking occurs without luminescence; no matter how carefully a crystal is cleaved along the very perfect cleavage on the pinacoid $\{100\}$, so that parting only occurs parallel to the cleavage plane, and with a minimum of shock, vivid luminescence always occurs; and on carefully cutting the crystals in directions perpendicular to the cleavage, so that very little parting occurs along this plane, a brilliant flash almost invariably results.

An exhaustive examination of the properties of the crystals was made, in order to allow of some cause being assigned to this peculiar phenomenon; it was at first thought that the crystals might be hemimorphic or hemihedral, and that the luminescence might be in some way related to the polar properties inseparable from hemimorphism. No positive evidence was, however, obtained in this direction.

Crystals of orthobenzoicsulphinide, obtained by other methods than the above, showed no triboluminescence. The substance on heating sublimes in long glistening needles, which are morphologically and optically identical with the crystals deposited from acetone, but show no triboluminescence.

After the publication of the paper referred to, Luigi Brugnatelli (Zeits. f. Krystallographie, 1897, 27, 78) gave particulars of several similar cases found by him amongst derivatives of santonin prepared by Amerigo Andreocci (Atti d. R. Accad. Linc., I895, [5a], 2, 28). The monosymmetric crystals of ethylisodesmotroposantonin, $\mathrm{C}_{12} \mathrm{H}_{13}(\mathrm{OEt})$ a $_{\mathrm{C}}^{\mathrm{O}: \mathrm{O}}$ emit a yellow luminescence when crushed; the monosymmetric crystals of the enantiomorphously related dextro-and lævo-ethylic santonite, $\mathrm{C}_{12} \mathrm{H}_{14}(\mathrm{OH}) \mathrm{CHMe}$.COOEt, and the monosymmetric crystals of lævodesmotroposantonous acid, $\mathrm{C}_{12} \mathrm{H}_{14}(\mathrm{OH}) \mathrm{CHMe}$. COOH, all give a yellowish-green triboluminescence. Lævoethyldesmotroposantonous acid $\mathrm{C}_{12} \mathrm{H}_{14}(\mathrm{OE} t) \mathrm{CHMe.COOH}$, crystallises in hemihedral anorthic crystals, which when crushed glow with a beautiful emerald-green light.

Crystals of saccharin have also been examined by W. Arnold (Zeits. f. Kryst., 1896, 27, 92), who describes their triboluminescence as "stark," and states that that of crystallised hippuric acid $\mathrm{C}_{6} \mathrm{H}_{5}$. CO.NH.CH, $\mathrm{COOH}$, is "sehr stark." 
Since the publication of my paper in 1895 , I have made a few observations of interest to which I may now refer. Crystals of saccharin which, when freshly prepared, flash brilliantly on crushing, gradually lose this property, and after a few weeks' preservation show no appreciable triboluminescence. Further, in order to obtain crystals which exhibit a brilliant triboluminescence, the impure commercial saccharin must be crystallised from acetone ; a carefully purified specimen of saccharin, when crystallised from acetone, yielded crystals which do not phosphoresce at all when broken. Both of these points are of great importance as affording possible clues to the cause of this strange property ; it would be of interest to ascertain whether the triboluminescence of cane sugar, hippuric acid, and other substances is in any way characteristic of the freshly prepared crystals, and is dependent on the presence of traces of impurity. Another point of great interest, indicating that triboluminescence is probably not a property of the chemical molecules, but only of the crystalline structure, is noted in Brugnatelli's paper; although the crystals of dextro-and lævo-ethylic santonite show brilliant triboluminescence, the anorthic crystals of the racemic compound of these two substances exhibit no triboluminescence.

In concluding this note on triboluminescence, may I point out that the study of the subject from a physical standpoint should be extremely fertile. Saccharin may now, thanks to commercial enterprise, be obtained in large quantities at a comparatively low cost.

William JaCkson POPE.

\section{EXPLOSIONS CAUSED BY COMMONLY OCCURRING SUBSTANCES.}

$T H E$ occurrence of a serious explosion in the Capitol at Washington, last November, has led the President of the American Society, Prof. C. E. Munroe, to address the members on the subject of explosions caused by commonly occurring substances. The address, which is fully reported in a recent number of Science, forms an interesting and valuable history of the subject, beginning with the well-known flour mills expiosion in Glasgow in 1872. A similar explosion in Minneapolis, in I878, shattered walls six feet thick at the base, and projected sheets of corrugated iron to a distance of more than two miles. The origin of the explosion was traced to the striking of fire by a pair of mill-stones through the stopping of the "feed." Dust explosions have also been recorded in connection with oatmeal, starch, rice, malt, spice, saw-dust, soap and zinc. In pharmacy and the arts accidents have arisen from various mixtures of combustible substances and oxidising agents in connection with matches, chlorate of potash lozenges, sodium peroxide and sodium bisulphite mixtures. Among substances explosive per se which have given rise to accidents, are erythryl nitrate, ammonium nitrate, and various nitroso compounds, diazo bodies, diamides, hydrazoic acid and its compounds, hydroxylamines, chlorates, carbonyl compounds, permanganates, peroxides, chlorides and iodides. Prof. Munroe devotes a considerable amount of space to explosions arising from the use and storage of petroleum, drawing his information mainly from English sources. He adds to the examples, well known in connection with British shipping, of explosions caused by the use of "driers" and paints made up with volatile hydrocarbons. A remarkable explosion occurred at Rochester, New York, in I 887, owing to the leakage of twelve thousand gallons of naphtha from a dislocated iron main into a sewer. The explosive mixture of air and vapour was ignited from a boiler fire through an untrapped watercloset, and the explosion, besides causing loss of life, destroyed three large mills. Prof. Munroe states that of substances supposed to impart safety to kerosene, alum and sal-ammoniac are practically insoluble in the liquid, and are of no effect ; whilst camphor, though it raises the flash-point, causes the vapour mixed with air to have a lower temperature of ignition.

After dealing with compressed gases and coal-dust explosions, Prof. Munroe reverts to the Washington explosion, and shows that it was due primarily to the escape of gas through a governor into a "live" 4 -inch main, owing to a sudden doubling of pressure. The gas found its way through a labyrinth of passages and compartments in a section of the building, and when the stratum of gas reached down to the level of some burning gas jets, ignition took place and the explosion was propagated in all directions, its intensity and range being increased by the disturbance of large accumulations of inflammable dust.

\section{TECHNICAL EDUCATION IN GERMANY.1}

$G$ ERMAN merchants and manufacturers are alive to the importance of increasing the efficiency of the mechanics and artisans, and of improving the quality of their goods. According to the United States Consul at Hanover, they appear to be resolved that "Made in Germany" shall no longer pass as a term of opprobrium, but be a synonym of excellent materials and good workmanship. A meeting took place recently in Hanover, which is likely to exercise a very important influence in this direction. It was in the nature of a conference, under Governmental sanction and direction, to discuss German trade and manufacturing interests, and to devise plans for their extension and improvement. It was held at the instance of the Prussian Minister of Trade and Commerce, and was presided over by the Oberregierungs President of the Province of Hanover, Count Stolberg. Representatives of the Government from Berlin, the highest officials of the Hanoverian provincial and municipal administrations, leading manufacturers and business men, delegates from the Chamber of Commerce, the manual training and artistic trade schools, and from the working men's trade unions, attended and took part in the deliberations. As a result of the conference, it was unanimously resolved: (I) To establish at once in the city of Hanover advanced lecture courses, in which artisans and apprentices in all trades shall have an opportunity to complete their mechanical education, and be instructed by experts how to install and manage a model workshop, and work and use machines and tools to the greatest advantage. Instruction will also be given in book-keeping, the making and rendering of accounts, the making of estimates of the cost of work and materials, how to conduct business correspondence, drawing, and other practical branches. (2) The supervision and control of the said lecture courses shall be under the direction of a commission composed of representatives from the Imperial. provincial, and municipal administrations, the Chamber of Commerce, the manual and art schools, and from the trade unions. (3) The first course of lectures will be for cabinetmakers, locksmiths, shoemakers and tailors. Those for other trades will follow. (4) A fee for tuition will be exacted from mechanics able to pay, but those unable to pay will be instructed free. Funds for the payment of the tuition of the poor will be provided by the Hanover provincial and municipal Governments. (5) Only mechanics and apprentices will be admitted to the classes whose theoretical and practical knowledge is such as to give promise of success as students. The Commission has power in all cases to decide as to qualification of applicants for admission. (6) Teachers are to be selected by the Commission, and confirmed by the Minister of Trade and Commerce. (7) The cost of the establishment and maintenance of the lectures is to be supplied by the General Government, and that of the province and city of Hanover, together with the trades unions, the Chamber of Commerce, and others interested therein. (8) It is further intended that great care shall be used in teaching apprentices how to obtain the most practical advantages from the knowledge obtained by them in the classes. To this end, the creation of working-men's co-operative societies is to be urged. (9) A permanent exhibition of all power machines and tools used in the small trades is to be established in the Gewerte Halle (Industrial Hall) in Hanover. The machines exhibited there are to be worked by competent mechanics, who, on request, will exhibit their uses and management to all inquirers. In connection with the machine exhibition, there will also be established an exhibition of sample products, in process of manufacture, as well as finished. (10) In order to enable small manufacturers and tradesmen to purchase their raw materials at wholesale prices, and to facilitate the sale of their products, the formation of co-operative stores is to be encouraged. Consul Anderson has been informed that the establishment of these courses of lectures to mechanics is the initial move in a general plan to be in all the main labour centres of Germany, dependent upon the success of this experiment.

\section{UNIVERSITY AND EDUCATIONAL INTELLIGENCE.}

OXFORD. - The following are the chief lectures advertised for the ensuing term in the Faculty of Natural Science, in addition to the elementary courses:-Prof. Gotch, on the nervous system; Dr. Mann, on histology of sense organs; Mr. Burch,

1 Reprinted from the Journal of the Society of Arts (April 14). 